\title{
Loss of Distal Axons and Sensory Merkel Cells and Features Indicative of Muscle Denervation in Hindlimbs of P0-Deficient Mice
}

\author{
Regula Frei, ${ }^{1,3}$ Sandra Mötzing, ${ }^{1}$ Ilka Kinkelin, ${ }^{2}$ Melitta Schachner, ${ }^{4}$ Martin Koltzenburg, ${ }^{1}$ and \\ Rudolf Martini 1,3 \\ Departments of ${ }^{1}$ Neurology and ${ }^{2}$ Dermatology, University of Würzburg, D-97080 Würzburg, Germany, ${ }^{3}$ Department of \\ Neurobiology, Swiss Federal Institute of Technology, CH-8093 Zürich, Switzerland, and 4Zentrum für Molekulare \\ Neurobiologie, University of Hamburg, D-20246 Hamburg, Germany
}

\begin{abstract}
Mice lacking the major Schwann cell myelin component P0 show a severe dysmyelination with pathological features reminiscent of the Déjérine-Sottas syndrome in humans. Previous morphological and electrophysiological studies on these mice did not only demonstrate a compromised myelination and myelin maintenance, but were suggestive of an impairment of axons as well. Here, we studied the axonal pathology in P0deficient mice by quantitative electron microscopy. In addition, we investigated epidermal receptor end organs by immunocytochemistry and muscle pathology by histochemistry.

In proximal sections of facial and femoral nerves, axon calibers were significantly reduced, whereas the number of myelincompetent axons was not diminished in 5- and 17-month-old P0-deficient mice. However, in distal branches of the femoral and sciatic nerve (digital nerves innervating the skin of the first
\end{abstract}

Inherited demyelinating neuropathies are chronic disorders of the peripheral nervous system that cause muscle weakness and sensory dysf unction. Particularly in lower limbs, irreversible degenerative processes such as muscle atrophy are typical, and the increasing loss of muscle strength results in malformation of the skeleton (Dyck et al., 1993). So far, four genes have been identified that are related to these disorders, including the peripheral myelin protein (PMP) 22, the myelin protein zero (MPZ, P0), the gap junction protein connexin 32 (Cx32), and the early growth responsive gene (EGR) 2 (Warner et al., 1998) (for review, see De Jonghe et al., 1997; Martini et al., 1998). Depending on the mutated gene and on the severity of the resulting disorder, different subforms can be distinguished. These include various types of the Charcot-Marie-Tooth (CMT) disorder and particularly severe variants, such as the Déjérine-Sottas syndrome (DSS) and congenital hypomyelination (Warner et al., 1998) (for review, see De Jonghe et al., 1997; Martini et al., 1998).

A common histopathological feature in nerve biopsies is the presence of abnormal myelin sheaths and reduced numbers of

\footnotetext{
Received March 5, 1999; revised May 3, 1999; accepted May 7, 1999.

The study was supported by the Swiss National Research Foundation (R.M.), by the Deutsche Forschungsgemeinschaft (R.M.), by research funds of the University of Würzburg, and by the European Union (Clinical, Genetic, and Functional Analysis of Peripheral Neuropathies: An Integrated Approach). We are grateful to Carsten Wessig, Stefano Carenini, and K. V. Toyka for discussions, Kathrin Rohner and Heinrich Blazyca for skillful technical assistance, and Michael Sendtner and Hans Lassmann for sharing unpublished data.

Correspondence should be addressed to Rudolf Martini, Department of Neurology, Section of Developmental Neurobiology, University of Würzburg, JosefSchneider-Strasse 11, D-97080 Würzburg, Germany.

Copyright (C) 1999 Society for Neuroscience 0270-6474/99/196058-10\$05.00/0
}

toe) the numbers of myelin-competent axons were reduced by $70 \%$ in 6-month-old P0-deficient mice. Immunolabeling of foot pads revealed a corresponding loss of Merkel cells by $75 \%$, suggesting that survival of these cells is dependent on the presence or maintenance of their innervating myelinated axons. In addition, quadriceps and gastrocnemius muscles showed pathological features indicative of denervation and axonal sprouting. These findings demonstrate that loss of an important myelin component can initiate degenerative mechanisms not only in the Schwann cell but also in the distal portions of myelinated axons, leading to the degeneration of specialized receptor end organs and impairment of muscle innervation.

Key words: hereditary neuropathies; animal models; axonopathy; axonal degeneration; Schwann cell; myelin myelin profiles (Dyck et al., 1993), a finding that is in concord with the fact that the culprit genes are expressed by Schwann cells. Electrophysiologically, the disrupted myelin formation or myelin degeneration is reflected by lowered conduction velocities, increased muscle response latencies, and dispersed compound action potential profiles (Dyck et al., 1993). Paradoxically, the disorders are often associated with reduced amplitudes of compound action potentials, a feature that is indicative of compromised axon properties rather than of myelin disruption (Sghirlanzoni et al., 1992; Berciano et al., 1998; Marrosu et al., 1998). The surprising observation that mutations in Schwann cell-associated genes cause axonal abnormalities or damage is of particular interest, because dysfunction of axons may have robust functional consequences.

A tight link between the Schwann cell phenotype and axonal properties has been experimentally demonstrated in the Trembler (Tr) mouse (De Waegh et al., 1992), a spontaneous mouse mutant carrying an Asp to Gly substitution at codon 150 of the CMTrelated gene PMP22 (Suter et al., 1992). In mice deficient in the myelin-associated glycoprotein (MAG), reduced neurofilament spacing, altered phosphorylation of neurofilaments, and axonal loss are leading features in the peripheral nerves of these mutants (Fruttiger et al., 1995a; Carenini et al., 1997; Yin et al., 1998). Axonal impairment has also been described in sciatic and femoral nerves of mice homozygously deficient in P0 (Giese et al., 1992), an animal model for P0-related DSS (Martini et al., 1995a; Martini, 1997). To determine the extent of axonal changes in these mice, we measured the calibers of myelinated axons and quantified the numbers of myelinated axons in various peripheral nerves 
Table 1. Number of nerves of $\mathrm{P} 0++$ and $\mathrm{P} 0--$ mice analyzed at different postnatal ages

\begin{tabular}{|c|c|c|c|c|c|c|c|c|}
\hline \multirow[b]{2}{*}{ Age (months) } & \multicolumn{4}{|c|}{$\mathrm{P} 0++$} & \multicolumn{4}{|c|}{$\mathrm{P} 0--$} \\
\hline & $\mathrm{CF}$ & FQ & FS & $\mathrm{TN}$ & CF & FQ & FS & $\mathrm{TN}$ \\
\hline 1.5 & & & & 5 & & & & 3 \\
\hline 4 & & & & 2 & & & & 4 \\
\hline 6 & 4 & 4 & 4 & 4 & 3 & 3 & 3 & 3 \\
\hline 17 & 2 & 4 & & & 5 & 5 & & \\
\hline
\end{tabular}

$\overline{\mathrm{CF} \text {, Cervical branch of facial nerve; FQ, femoral quadriceps nerve; FS, femoral }}$ saphenous nerve; TN, toe nerves.

by electron microscopy. We found that in proximal parts of peripheral nerves, axons were reduced in their calibers but not in their numbers. In distal parts of the nerves, the number of axons was drastically reduced, accompanied by muscle denervation and a significant loss of sensory Merkel cells.

\section{MATERIALS AND METHODS}

Animals. Wild-type mice $(\mathrm{P} 0++)$ and $\mathrm{P} 0$-deficient mice $(\mathrm{P} 0--)$ were taken from our own breeding colony. The genotypes were determined by their striking and typical phenotype (Giese et al., 1992). In some mice determined to be P0-- mice, presence of the inserted neo gene was confirmed by PCR using appropriate primers.

Table 1 indicates the number of nerves of $\mathrm{P} 0++$ and $\mathrm{P} 0--$ mice investigated at different postnatal ages.

Surgery. To confirm the sciatic and saphenous origin of the plantar and dorsal toe nerves, respectively, sciatic or saphenous nerves were transected as described (Fruttiger et al., 1995b), followed by an electron microscopic investigation of nerve lesion-induced degeneration in the first toe of the lesioned side at postoperative day 14 .

Tissue preservation for light and electron microscopy. Mice were transcardially perfused with $0.1 \mathrm{~m}$ cacodylate buffer containing $4 \%$ freshly depolymerized paraformaldehyde and $2 \%$ glutaraldehyde. Facial and femoral nerves comprising quadriceps and saphenous branches were dissected at the level of the stylomastoid foramen and of the inguinal ligament, respectively. For analysis of the facial nerve, we selected the branch that bifurcates into the cervical branch, innervating the platysma, and the marginal mandibular branch, innervating the muscles of the lower lip. For simplicity, we called this common branch cervical branch. In addition, the first toes containing the terminal branches of the femoral saphenous and the sciatic nerves were dissected. Tissue specimens were post-fixed for 12-24 hr in the perfusion fixative and processed for transmission electron microscopy as described (Carenini et al., 1997).

Immunolabeling of Merkel cells. Immunolabeling of Merkel cells was performed on 16- $\mu \mathrm{m}$-thick acetone-fixed serial cryosections of foot pads from 1.5- and 6-month-old $\mathrm{P} 0++$ and $\mathrm{P} 0--$ mice using antibodies to cytokeratin 20 as described previously (Airaksinen et al., 1996). Instead of fluorescent markers, biotinylated secondary anti-mouse antibodies and an avidin-biotin complex coupled to horse radish peroxidase were used (Sigma, St. Louis). Peroxidase activity was detected by a Tris-buffered solution containing diaminobenzidine- $\mathrm{HCl}$ and $0.03 \% \mathrm{H}_{2} \mathrm{O}_{2}$.

Immunolabeled Merkel cells were counted on every second section. The total lengths of the dermis/epidermis interfaces of these sections were measured, and the number of Merkel cells per millimeter of dermis/epidermis interface was determined. Statistical analysis was performed using a Student's $t$ test.

Quinacrine fluorescence of Merkel cells. To quantify the number of Merkel cells in the back skin, we used the fluorescent vital dye quinacrine (quinacrine hydrochloride, Sigma-Aldrich, Deisenhofen, Germany), which is taken up by Merkel cells after it is injected systemically (Airaksinen et al., 1996). Six-month-old $\mathrm{P} 0++$ and $\mathrm{P} 0--$ mice $(n=4$ in each group) were injected intraperitoneally with quinacrine/saline solution (1.5 mg quinacrine/100 gm body weight) as described previously (Airaksinen et al., 1996). After 18-20 hr, the animals were killed by $\mathrm{CO}_{2}$ inhalation, and the back skin was shaved and depiliated with depiliating cream. Approximately $1 \times 1 \mathrm{~cm}$ of back skin was excised and embedded with the hairy side up in Aquatex (Merck, Darmstadt, Germany). Wholemounts of skin were viewed under an Axiophot epifluorescence microscope with a filter for fluorescein isothiocyanate. The entire tissue was examined, and the number of Merkel cells per square centimeter was determined. Statistical analysis was performed using a Student's $t$ test.

Type grouping of muscle fibers. Quadriceps and gastrocnemius muscles were dissected from 6-month-old $\mathrm{P} 0++$ and $\mathrm{P} 0--$ mice followed by immediate freezing in liquid nitrogen-cooled isopentane. Cryosections (12 $\mu \mathrm{m}$ thick) were mounted on poly-L-lysine-coated glass slides and air-dried. Myofibrillar actomyosin ATPase histochemistry has been performed at pH 4.3, 4.6, and 9.4 as described (Hämäläinen and Pette, 1993).

Morphometry. For quantitative analysis, all myelinated axons (including axons without myelin but having achieved a 1:1 ratio with Schwann cells and abnormally myelinated axons in $\mathrm{P} 0--$ mice) of the facial cervical nerve and the femoral quadriceps and saphenous nerves were considered. In addition, the myelinated axons of the first toe were investigated.

The numbers and diameters of myelinated axons were determined on electron micrographs at a final magnification of 2000-4000×. For each nerve, all axons were considered. The axons were categorized according to their diameters $(<1 \mu \mathrm{m}, 1-3 \mu \mathrm{m}, 3-6 \mu \mathrm{m},>6 \mu \mathrm{m})$. Significance of differences between mean values was determined by a two-sided Student's $t$ test.

\section{RESULTS}

To study the morphological appearance and number of axons in mice deficient in $\mathrm{P} 0$, we investigated various peripheral nerves. In particular, we selected two muscle nerves, the cervical branch of the facial nerve and the femoral quadriceps nerve. Because we have shown previously that the neuropathy in $\mathrm{P} 0$-deficient mice progresses with age, we investigated the mice at 6 and 17 months. In addition to the muscle nerves, we scored the saphenous nerve, a cutaneous and particularly long branch of the femoral nerve, at 6 months of age. The cervical facial nerve was investigated $\sim 4$ $\mathrm{mm}$ distal to the stylomastoid foramen, the femoral quadriceps, and saphenous nerves at the level of the inguinal ligament.

\section{Reduced axon diameters in peripheral nerves of P0-deficient mice}

In peripheral nerves of $\mathrm{P} 0++$ mice, axons of larger caliber were always surrounded by normal myelin sheaths. In $\mathrm{P} 0--$ mice, various forms of abnormal axon-Schwann cell units were found in all nerves investigated. As shown previously, axons had either achieved a 1:1 relationship to Schwann cells without myelin or were surrounded by abnormally compacted myelin (Giese et al., 1992; Martini et al., 1995b; Carenini et al., 1999). For simplicity, axons that had achieved a 1:1 relationship with Schwann cells and axons surrounded by abnormal myelin were considered to be abnormally myelinated axons. A typical pathological feature in the nerves of the $\mathrm{P} 0--$ mice was the presence of supernumerary Schwann cells forming onion bulbs around abnormal axonSchwann cell units. Such onion bulbs are indicative of myelin degeneration-induced Schwann cell proliferation (Martini, 1997).

\section{Cervical branch of the facial nerve}

In 6- and 17-month-old $\mathrm{P} 0++$ mice, the cervical branch of the facial nerve $(\mathrm{CF})$ contained $1180( \pm 180)$ myelinated axons (Fig. $1 A$ ). Approximately $80 \%$ of the myelinated axons had diameters between 3 and $6 \mu \mathrm{m}$ (Fig. $1 B$ ). Myelinated axons with diameters smaller than $1 \mu \mathrm{m}$ were apparently absent, and axons exceeding 6 $\mu \mathrm{m}$ were rarely found. In 6- and 17-month-old $\mathrm{P} 0--$ mice, a similar number of larger caliber axons was determined as in $\mathrm{P} 0++$ mice (Fig. 1A). However, a significant reduction in axon caliber was found at both ages (Fig. $1 B$ ). Whereas in $\mathrm{P} 0++$ mice most myelinated axons were between 3 and $6 \mu \mathrm{m}$ in diameter, in P0 -- mice $\sim 70 \%$ of the axons had a caliber of $1-3 \mu \mathrm{m}$. Furthermore, axons displaying a diameter $<1 \mu \mathrm{m}$ were present in the mutants. 

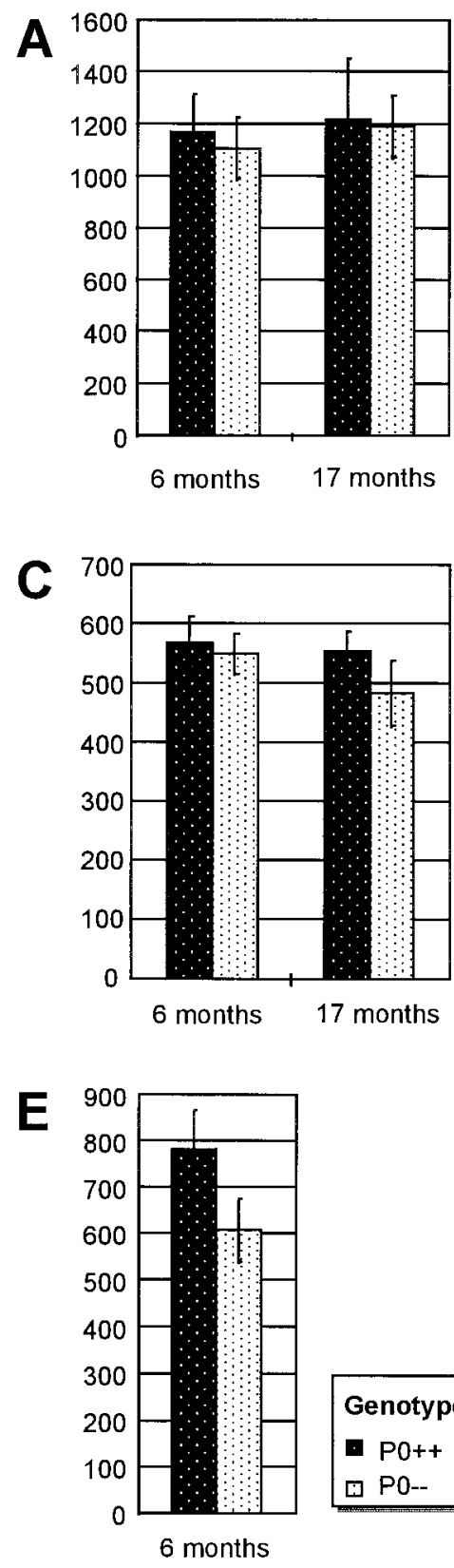
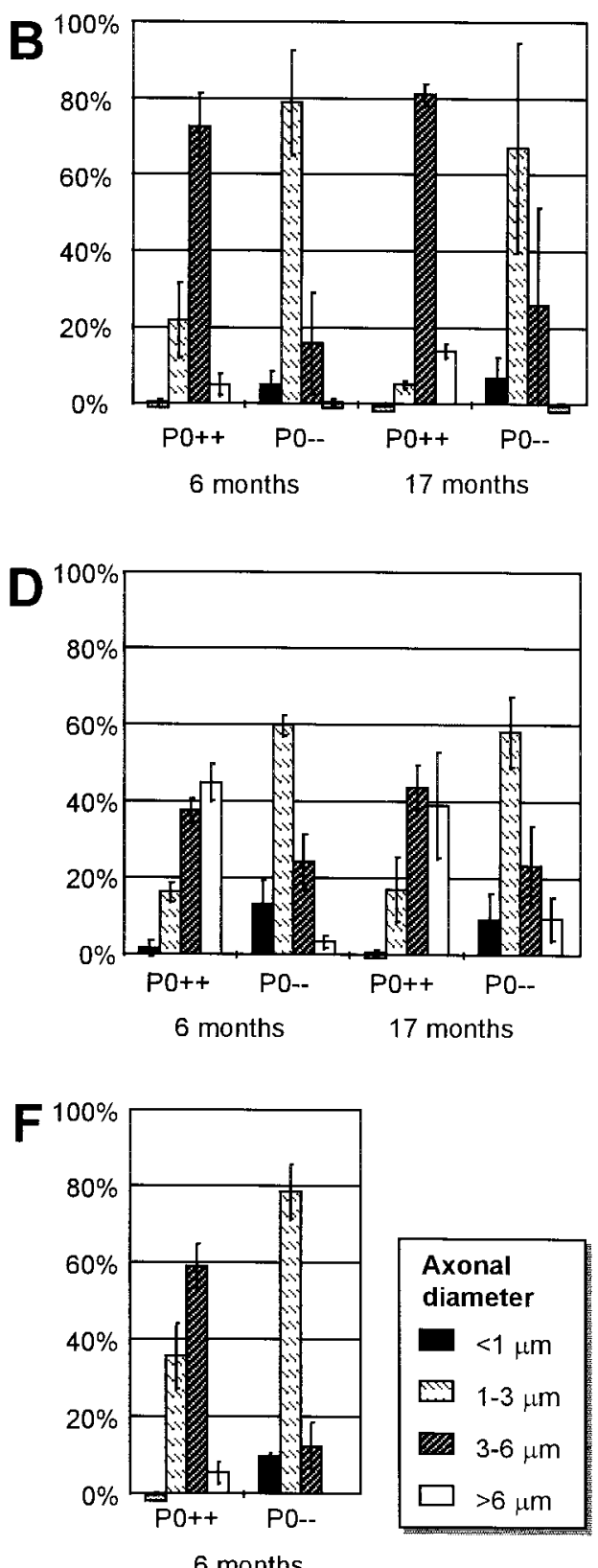

Figure 1. Representations of the number of myelin-competent axons $(A, C, E)$ and sizefrequency histograms $(B, D, F)$ of the femoral quadriceps nerve $(C, D)$, of the cervical branch of the facial nerve $(A, B)$, and of the femoral saphenous nerve $(E, F)$ of $\mathrm{P} 0++$ and $\mathrm{P} 0--$ mice. The total number of myelin-competent axons in the proximal nerves of $\mathrm{P} 0--$ mice is not significantly changed at all ages investigated $(A$, $C, E)(p>0.05)$. Note the reductions of axonal diameters in $\mathrm{P} 0--$ animals. All differences between $\mathrm{P} 0++$ and $\mathrm{P} 0--$ mice in the axon number per size category were significant. Mean \pm SD are shown. Inset in $E$ applies to $A, C, E$; inset in $F$ applies to $B, D, F$.

\section{Femoral quadriceps nerve}

The femoral quadriceps nerve (FQ) contains 560 ( \pm 40$)$ myelinated axons in both $\mathrm{P} 0++$ and $\mathrm{P} 0--$ mice (Fig. $1 C$ ). As shown in Figure $1 D$, most of the myelinated axons of $\mathrm{P} 0++$ mice were larger than $3 \mu \mathrm{m}$ in diameter, and $\sim 40 \%$ exhibited calibers of $>6$ $\mu \mathrm{m}$. In $\mathrm{P} 0--$ mice, however, the situation was dramatically changed (Fig. 1D). Most axons were $<3 \mu \mathrm{m}$ in diameter, and this shift to smaller caliber axons was at least partially at the expense of the categories containing axons with a diameter $>3 \mu \mathrm{m}$. Similar to the CF, a significant number of axons were $<1 \mu \mathrm{m}$ in $\mathrm{P} 0--\operatorname{mice}($ Fig. 1D).

\section{Femoral saphenous nerve}

In $\mathrm{P} 0++$ mice, the femoral saphenous nerve (FS) contains 780 $( \pm 80)$ myelinated axons (Fig. $1 E$ ). In $\mathrm{P} 0--$ mice, this number was reduced by $\sim 25 \%$, but this reduction was not statistically significant (Fig. 1E). A very significant change, however, was found when the axon calibers were compared (Fig. $1 F$ ). In $\mathrm{P} 0++$ mice the majority of the axons had a diameter between 3 and 6 $\mu \mathrm{m}$; in the mutants $80 \%$ of the axons had a diameter of $1-3 \mu \mathrm{m}$ only. Similar to the CF and FQ, a significant number of axons had a diameter of $<1 \mu \mathrm{m}$ in the $\mathrm{P} 0--$ mice. In all nerves of $\mathrm{P} 0--$ mice examined, electron microscopy revealed a substantially elevated density of neurofilaments in myelin-competent axons (see Fig. 4A,C).

\section{Reduced numbers of axons and features indicative of axonal degeneration in distal parts of FS and sciatic nerves of PO-deficient mice}

We have shown that in proximal aspects of three different peripheral nerves of $\mathrm{P} 0--$ mice axon calibers are significantly altered, but the number of myelinated axons was not significantly reduced. Because it is known that in inherited peripheral neuropathies the clinical and pathological alterations are usually most severe in the 

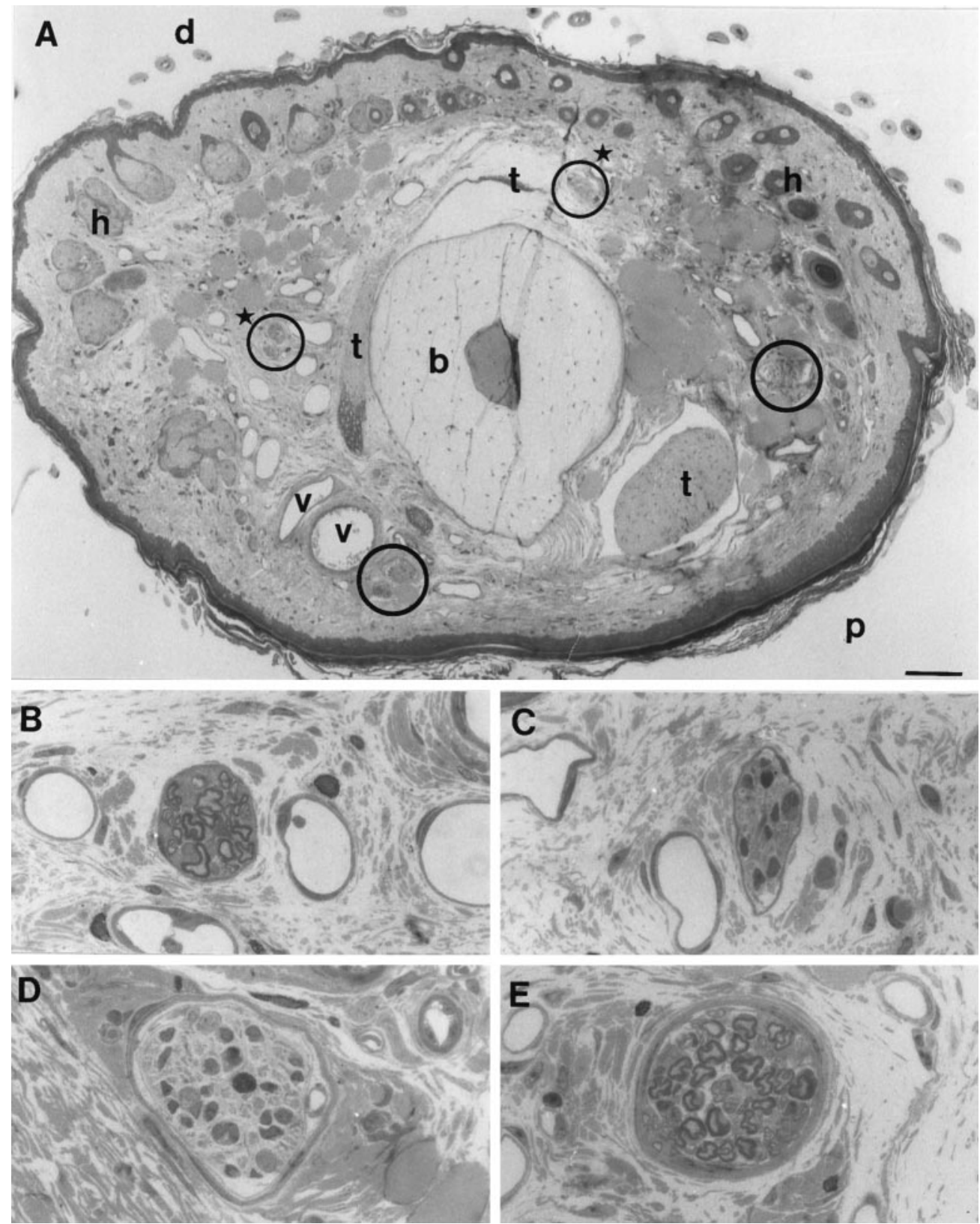

Figure 2. Micrographs of semithin cross sections of the base of the first toe of $\mathrm{P} 0++$ mice. A, Low-power micrograph of the toe showing the position of dorsal branches of the femoral saphenous nerve (circles with stars) and plantar branches of the sciatic nerve (circles). Dorsal $(B, C)$ and plantar $(D, E)$ nerve branches of the toe after transection of the sciatic $(B, D)$ and the femoral saphenous $(C, E)$ nerves. Wallerian degeneration in $C$ and $D$ reflects the femoral saphenous and sciatic nerve origin of the dorsal and ventral nerves, respectively. $b$, Bone; $d$, dorsal; $h$, hair follicles; $p$, plantar; $t$, tendons; $v$, vessels. Scale bar (shown in $A$ ): $A, 300 \mu \mathrm{m} ; B-E, 15 \mu \mathrm{m}$. lower parts of the extremities with features reflecting axonal damage (Dyck et al., 1993), we investigated the myelinated axons of the first toe. In cross sections through the basis of the first toe, two plantar and two dorsal nerves can be found (Fig. 2A). All myelinated axons innervating the plantar side are derived from the sciatic nerve, whereas the axons innervating the dorsal side are derived from the FS. These anatomical conditions were confirmed by transecting either the sciatic or the FS nerve of normal mice followed by studying the lesion-induced degeneration of axons in the respective location of the toe (Fig. $2 B-E$ ). When sciatic nerves had been transected, all axon-Schwann cell units from the plantar side degenerated (Fig. 2D), whereas transection of the FS resulted in the degeneration of all dorsal axon-Schwann cell units (Fig. 2C).

Each plantar nerve of a $\mathrm{P} 0++$ mouse contains $\sim 40$ myelinated axons, and each dorsal nerve contains $\sim 25$ myelinated axons. In addition, several small nerve branchlets derived from the FS can be detected in the dorsal aspect of the toe. When investigating the plantar and dorsal nerve branches in the toes of $\mathrm{P} 0--$ mice, we found a dramatic reduction of myelin-competent axons (Fig. 3). In general, the strongest reduction was found in 6-month-old $\mathrm{P} 0--$ mice, the oldest age investigated, with $\sim 50 \%$ reduction in the sciatic nerve derivatives (plantar) and $\sim 75 \%$ reduction in the FS branches (dorsal) (Fig. 3).

Whereas in the proximal parts of the peripheral nerves the abnormal axon-Schwann cell units were often associated with supernumerary Schwann cells reflecting myelin degenerationinduced Schwann cell proliferation, such features were not detectable in the distal nerve parts (Fig. 4). Instead, Schwann cell profiles reminiscent of bands of Büngner were occasionally found, suggesting previous axonal loss (Fig. $4 B$ ). The number of bands of Büngner, however, was clearly smaller than the number of putatively degenerated axons, possibly reflecting Schwann cell degeneration. 


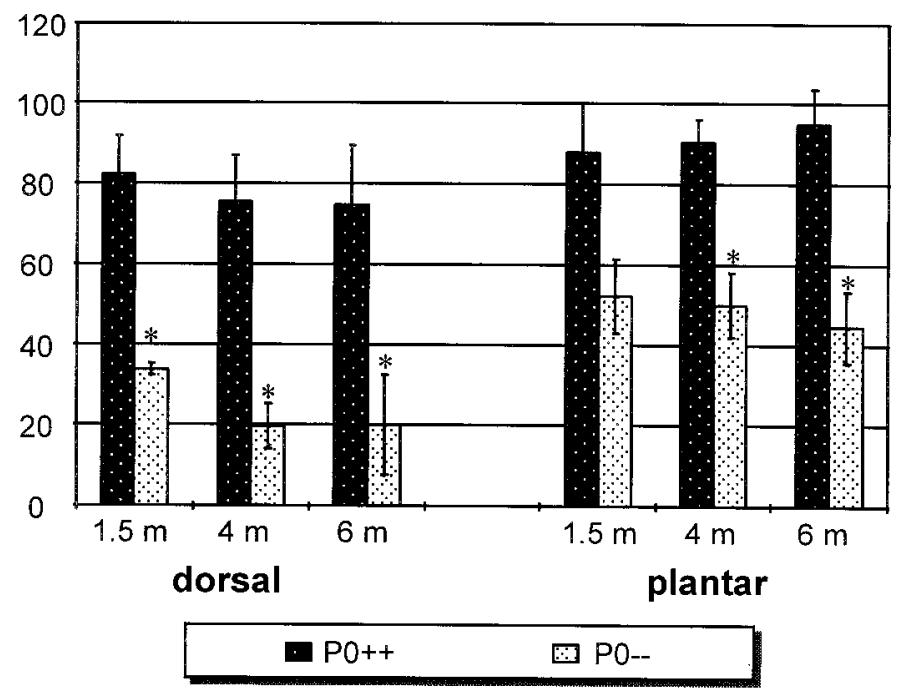

Figure 3. Representation of the number of myelin-competent axons in the nerve branches innervating the first toe of $\mathrm{P} 0++$ and $\mathrm{P} 0--$ mice at $1.5,4$, and 6 months $(m)$ of age. Note the significant reduction of axons in the distal nerve branches of 4 - and 6 -month-old $\mathrm{P} 0--$ mice $\left({ }^{*} p \leq 0.01\right)$. Mean \pm SD are shown.

\section{Reduced numbers of Merkel cells in P0-deficient mice}

It has been shown previously that sensory Merkel cells are dependent on the presence of their innervating myelinated axons (Mills et al., 1989; Airaksinen et al., 1996). We therefore determined the numbers of these specialized terminal cells in the foot pads by immunohistochemistry using antibodies to cytokeratin 20. Merkel cells were detected at the basal side of the epidermis close to the border of the dermis. In 1.5-month-old $\mathrm{P} 0++$ mice, approximately two $(1.8 \pm 0.4)$ Merkel cells per millimeter of dermis/epidermis interface could be detected. A similar number of Merkel cells could be found in 1.5-month-old $\mathrm{P} 0--$ mice $(1.5 \pm 0.3)$. At 6 months of age, the number of Merkel cells was not significantly altered in $\mathrm{P} 0++$ mice $(2.2 \pm 0.3)$, whereas in 6-month-old $\mathrm{P} 0--$ mice, the number of Merkel cells was reduced to $0.5( \pm 0.1)$ per millimeter of dermis/epidermis interface (Figs. $5 A, B, 6)$. Thus, in $\mathrm{P} 0--$ mice, loss of sensory axons is accompanied by a profound reduction of Merkel cells.

We also investigated the numbers of Merkel cells in the hairy skin of the back of $\mathrm{P} 0++$ and $\mathrm{P} 0--$ mice. For this purpose we injected mice with quinacrine, a fluorescent vital dye that labels Merkel cells (Airaksinen et al., 1996). Again, the number of Merkel cells was dramatically reduced in 6-month-old $\mathrm{P} 0--$ mice when compared with age-matched $\mathrm{P} 0++$ mice $(2.2 \pm 3.9$ Merkel cells per square centimeter in $\mathrm{P} 0--$ mice vs $248.5 \pm 86.8$ cells per square centimeter in $\mathrm{P} 0++$ mice; $p=0.003$ ) (Fig. 5C,D).

\section{Type grouping of muscle fibers}

Based on our observation that in cutaneous sensory nerves terminal axons degenerate and cause loss of Merkel cells, we considered the possibility that terminals of motor axons degenerate as well. As one possibility one might investigate distal aspects of muscle nerves close to their entrance into the corresponding muscle. However, because muscle nerves contain both motor and sensory axons, a loss of axonal profiles in muscle nerves does not stringently reflect a loss of motor axons. We therefore investigated quadriceps and gastrocnemius muscles with respect to established histopathological features that are indicative of loss of motor axons.
Although proximal aspects of motor nerves did not show significant axonal loss by electron microscopy, quadriceps muscles and, even more striking, gastrocnemius muscles of 6-month-old $\mathrm{P} 0--$ mice showed features indicative of denervation. For instance, in the lateral head of the gastrocnemius muscle of $\mathrm{P} 0++$ mice, ATPase staining at $\mathrm{pH} 4.3$ revealed a checkerboard pattern of relatively few, darkly labeled type I myofibers (Fig. 7A). Labeling for type II myofibers at $\mathrm{pH} 9.4$ resulted in a complementary staining pattern (data not shown). In the same muscle of P0-- mice, a grouped arrangement of type I myofibers was striking at $\mathrm{pH} 4.3$ (Fig. 7B). Such groups usually contained 4-7 tightly apposed myofibers. It is well established that such a staining pattern of grouped myofibers results from denervation of muscle fibers followed by collateral reinnervation by sprouts from neighboring motor units (De Girolami et al., 1997). In addition to the type grouping of myofibers, small, angulated myofibers that were often associated with grouped myofibers of normal size were detected (Fig. 7C,D). Such myofibers that were never detected in muscles from $\mathrm{P} 0++$ mice are indicative of denervation and represent neurogenic muscle atrophy (De Girolami et al., 1997).

\section{DISCUSSION}

We have shown that in mice deficient in the Schwann cell component $\mathrm{P} 0$ axonal properties are significantly changed. In proximal parts of peripheral nerves, axons are reduced in their calibers, but there is no significant loss of axons. In distal parts of the nerves, a robust loss of axons could be found as reflected by reduced numbers of axons, hallmarks of Wallerian degeneration, and features indicative of denervation of peripheral target organs.

\section{Myelinating glia cells determine axonal properties and axon survival}

The finding that axonal properties, such as axon size, are strongly dependent on glial partners has been described in various different systems. In MAG-deficient mice, myelination is initially normal, but in mice older than several months, axons and myelin degenerate (Fruttiger et al., 1995a; Carenini et al., 1997). A characteristic abnormality is the presence of paranodal myelin tomacula (Carenini et al., 1997; Yin et al., 1998). These tomacula have been suggested to form as a result of reduced axon calibers at the paranode caused by reduced neurofilament phosphorylation and spacing (Yin et al., 1998). However, it is also conceivable that myelin tomacula cause a physical constriction of axons attributable to a local overproduction of myelin turns, as has been proposed in other tomaculous peripheral neuropathies (Meier and Moll, 1982; Adlkofer et al., 1997). This constriction could lead, in turn, to axonal strangulation. In a very elegant series of experiments, De Waegh and colleagues transplanted nerve stumps from Trembler (Tr) mice into transected nerves of wildtype mice, allowing regrowing axons from wild-type mice to become myelinated by Schwann cells from Tr mutants (De Waegh and Brady, 1990; De Waegh et al., 1992). Abnormal Schwann cells of Tr mice were associated with smaller diameters of the wildtype axons and with a reduced degree of phosphorylation and spacing of the neurofilaments. Investigations on dorsal root ganglion neurons in vivo confirm the view that the Schwann cell phenotype can influence axon properties. Each dorsal root ganglion neuron extends a nonmyelinated stem process that bifurcates into two myelinated axons, one projecting into the spinal cord via the dorsal root and the other into the spinal nerve. In line with the view that glial cells can modify axonal properties, the nonmyelinated stem process of the neuron has a smaller diameter 

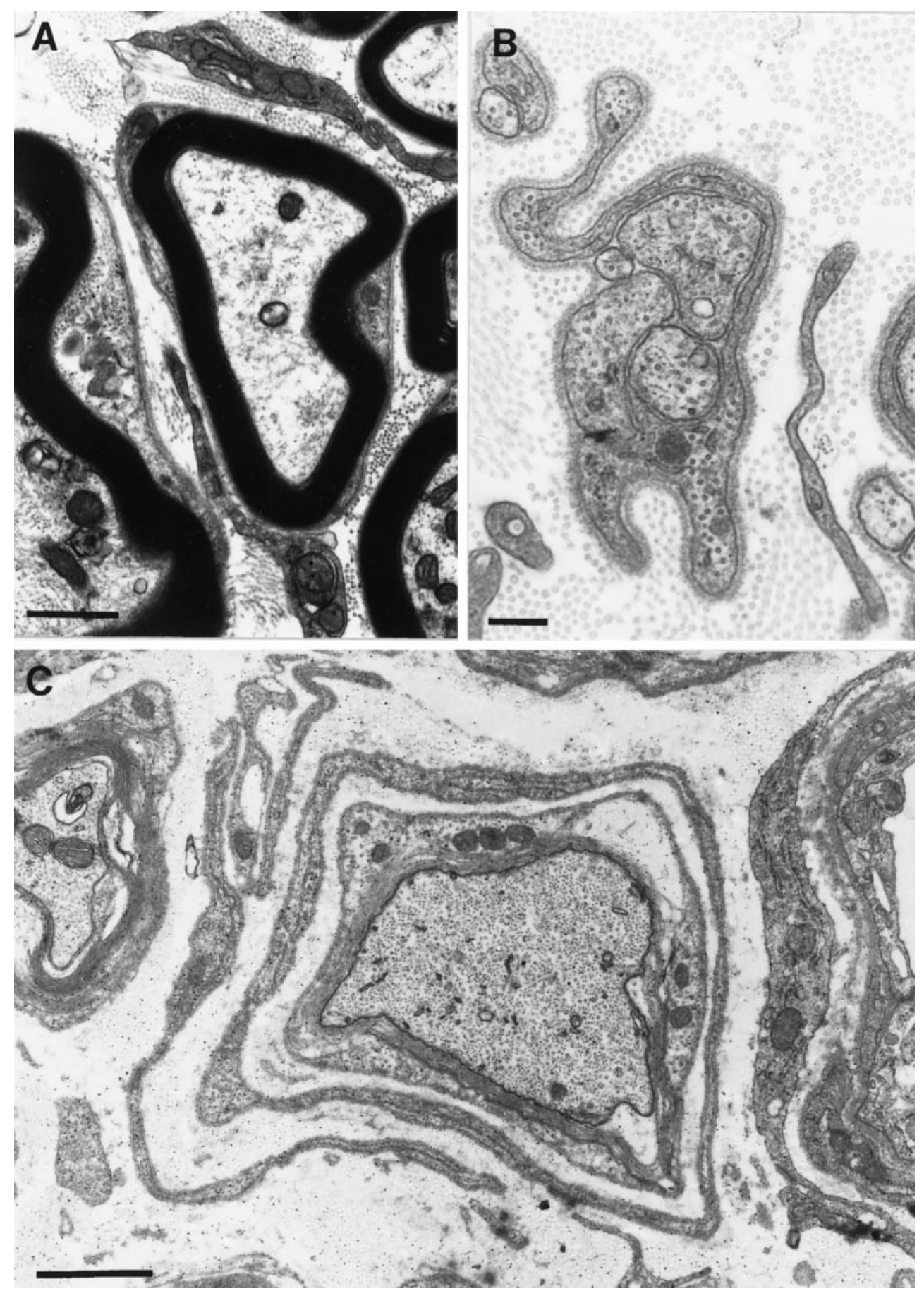

Figure 4. Electron micrographs of dorsal nerve branches of the first toe $(A, B)$ and of femoral quadriceps nerves $(C)$ of $\mathrm{P} 0++(A)$ and $\mathrm{P} 0--(B, C)$ mice. $A$, In the toes of $\mathrm{P} 0++$ mice, large axons with compact myelin sheaths are found. $B$, In the toes of $\mathrm{P} 0--$ mice, Schwann cell profiles reminiscent of bands of Büngner and representing Wallerian degeneration are pathological hallmarks. $C$, In proximal nerve parts of $\mathrm{P} 0--$ mice such as in femoral quadriceps nerves, abnormal myelin profiles associated with onion bulb cells are typical. Scale bars: $A, C, 1$ $\mu \mathrm{m} ; B, 0.25 \mu \mathrm{m}$.

and more dense neurofilament packing with lower phosphorylation status than the myelinated central and distal axons that are myelinated (Hsieh et al., 1994). The influence of myelinating glial cells on the axonal phenotype is not confined to Schwann cells. In optic nerves that have been depleted of oligodendrocytes by x-ray irradiation, the retina ganglion cell axons do not reach the calibers of myelinated retina ganglion cell axons (Colello et al., 1994). In line with this observation is the finding that enwrapping (Sanchez et al., 1996) or formation of compact myelin (Windebank et al., 1985) by oligodendrocytes leads to an increase of axonal calibers.

The loss of terminal axons in P0-deficient mice could be viewed as an extreme form of modulatory effect of glial cells on axonal properties. This phenomenon is not unique to mice deficient in P0 and has also been described in other experimental models or disorders. Sahenk and Chen (1998) recently demonstrated the vulnerability of distal axons from mice that are associated with mutant Schwann cells from humans. Sural nerve biopsies from patients with the X-linked form of CMT (CMTX) were grafted into transected nerves of immune-deficient nude mice. Axons were reduced in their calibers and displayed tightly spaced neurofilaments in the human xenografts. In distal but not in proximal aspects of the grafts, features indicative of axon degeneration were found. It is interesting to mention in this context that 

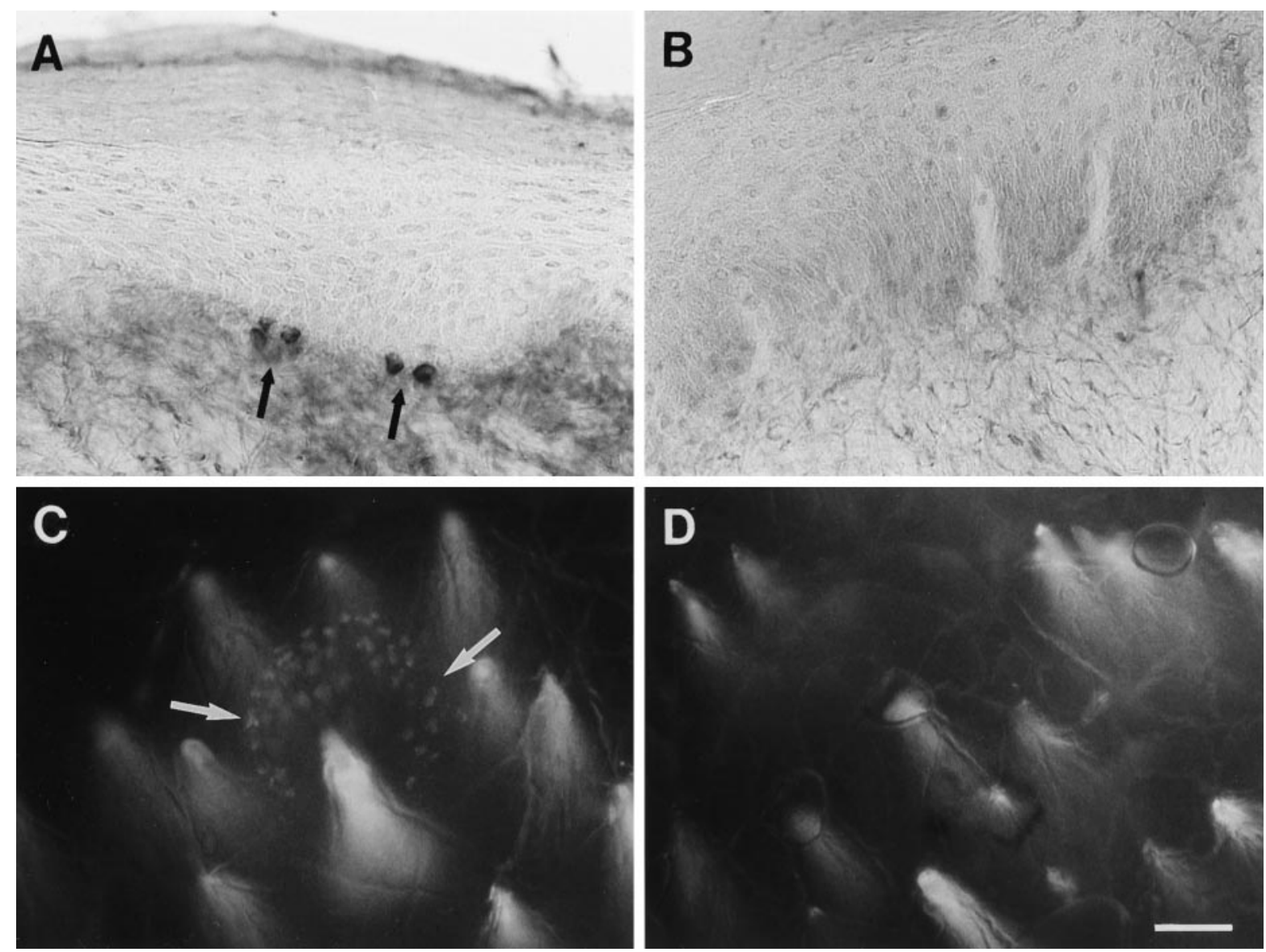

Figure 5. Light microscopy of Merkel cells in the glabrous $(A, B)$ and hairy skin $(C, D)$ of 6-month-old $\mathrm{P} 0++(A, C)$ and $\mathrm{P} 0--$ mice $(B, D)$ using antibodies to cytokeratin $20(A, B)$ and the fluorescent vital dye quinacrine $(C, D)$. $A$ and $B$ show cryosections of the footpads; $C$ and $D$ show whole-mount preparations of the back skin. $A$, In $\mathrm{P} 0++$ mice, Merkel cells (arrows) are detectable at the dermis/epidermis interface. $B$, In P0-- mice, the number of Merkel cells is strongly reduced so that long stretches of dermis/epidermis interface are devoid of Merkel cells. $C$, In hairy skin of P0++ mice, groups of Merkel cells (between arrows) representing touch domes are frequently found. $D$, In hairy skin of P0-- mice, Merkel cells are only rarely found. Highly fluorescent conical structures visible in hairy skin of both $\mathrm{P} 0++$ and $\mathrm{P} 0--$ mice represent the hair shafts. Scale bar (shown in $D$ ): $A$, $B, 25 \mu \mathrm{m}$; $C, D, 50 \mu \mathrm{m}$.

CMTX patients often suffer from an axonopathy rather than from a myelinopathy (Timmerman et al., 1996; De Jonghe et al., 1997; Sander et al., 1998), and mice deficient in Cx32 display features indicative of axon degeneration and regrowth at later ages (Anzini et al., 1997; Scherer et al., 1998). A robust effect of oligodendrocytes on survival of axon terminals has recently been demonstrated in multiple sclerosis. In this kind of neurological disorder, oligodendrocytes suffer from autoimmune attacks against particular membrane components (Archelos et al., 1998). The chronic impairment of oligodendrocytes apparently leads to a robust damage of axons as reflected by the frequent occurrence of terminal axonal ovoids in multiple sclerosis lesions (Trapp et al., 1998).

How can glial cells influence axonal properties and impair the survival of terminal axons? It is conceivable that molecules at the axon interface, such as MAG and possibly others, might be important mediators for the modulation of axonal properties by myelinating glial cells (De Waegh et al., 1992; Yin et al., 1998). Intriguingly, MAG is only weakly expressed at the Schwann cell-axon interface in P0-deficient mice (Carenini et al., 1999). The compromised axon-glia interactions could also alter slow axonal transport, as has been shown in trembler mutants (De Waegh and Brady, 1990; De Waegh et al., 1992). It is tempting to speculate that axonal receptors of glial molecules could locally modify axonal transport, possibly by signaling into the cell interior. It has recently been shown that particular mutations in the copper/zinc superoxide dismutase linked with amyotrophic lateral sclerosis in humans lead to impaired slow axonal transport of neurofilaments in transgenic mice, long before motor neuron decline occurs (Williamson and Cleveland, 1999). In this model, it is suggested that the impaired transport mechanism leads to the typical hallmarks of the disease, such as neurofilament-containing axonal swellings that result in axonal strangulation and eventually death of motor neurons (Williamson and Cleveland, 1999). In the case of inherited neuropathies, we propose a different mechanism, because axonal swellings and death of motor neurons are not hallmarks of these diseases. It is conceivable that in gliamediated neuropathies, impaired slow axonal transport in all parts of the nerve leads to a deprivation of vital cell soma-derived molecules, particularly in the distal aspects of the axons. This in turn could induce local detrimental mechanisms that eventually lead to the decline of the axon terminal, whereas proximal aspects of the axons and the neuronal cell bodies (H. Lassmann, personal communication; M. Sendtner, personal communication) remain preserved. The implication of anterograde axonal transport in the degeneration of axons in various forms of hereditary neuropa- 


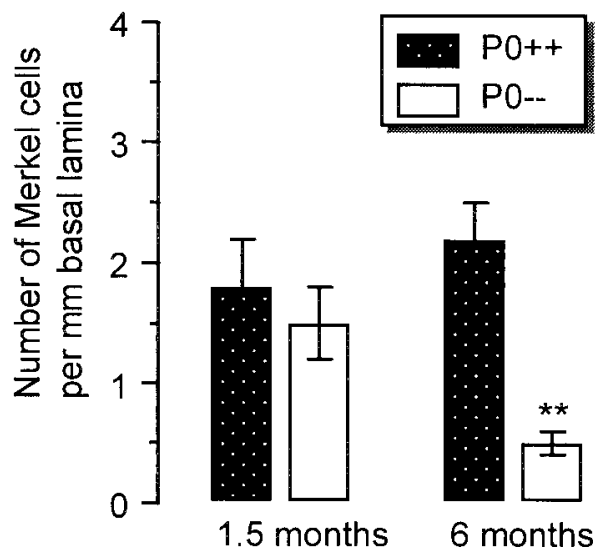

Figure 6. Quantification of Merkel cells in the glabrous skin of $\mathrm{P} 0++$ and $\mathrm{P} 0--$ mice. At the age of 6 , but not at 1.5 months, the number of Merkel cells in the skin of $\mathrm{P} 0--$ mice is significantly reduced compared with age-matched $\mathrm{P} 0++$ mice $(* * p<0.01)$. Mean $\pm \mathrm{SD}$ are shown. thies could explain the paradoxical observation that although all myelinating Schwann cells are abnormal, degeneration of axons is most severe at the distal ends of long nerves (Dyck et al., 1993). On the other hand, it is conceivable that Schwann cells at the terminal regions of the nerves suffer particularly severely from the absence of $\mathrm{P} 0$ and cause distal axon loss. We consider this possibility unlikely, however, because there is no evidence for such a mechanism, neither in young $\mathrm{P} 0$-deficient mice nor in other myelin mutants (Martini, unpublished observations).

\section{Clinical implications}

The fact that axon-glia interactions result in robust axonal changes has important clinical implications. A particularly striking phenomenon in our mouse model is the loss of axons at distal aspects of longer nerves. Interestingly, recent electrophysiological studies in young children diagnosed as CMT1A patients revealed that the first pathophysiological signs of the disease are a reduction of the amplitude of compound muscle action potentials, possibly reflecting axonal degeneration (Garcia et al., 1998). Similarly, several patients suffering from CMTX have previously been misdiagnosed as CMT2 because of a robust reduction of the amplitude of compound action potentials that is indicative of

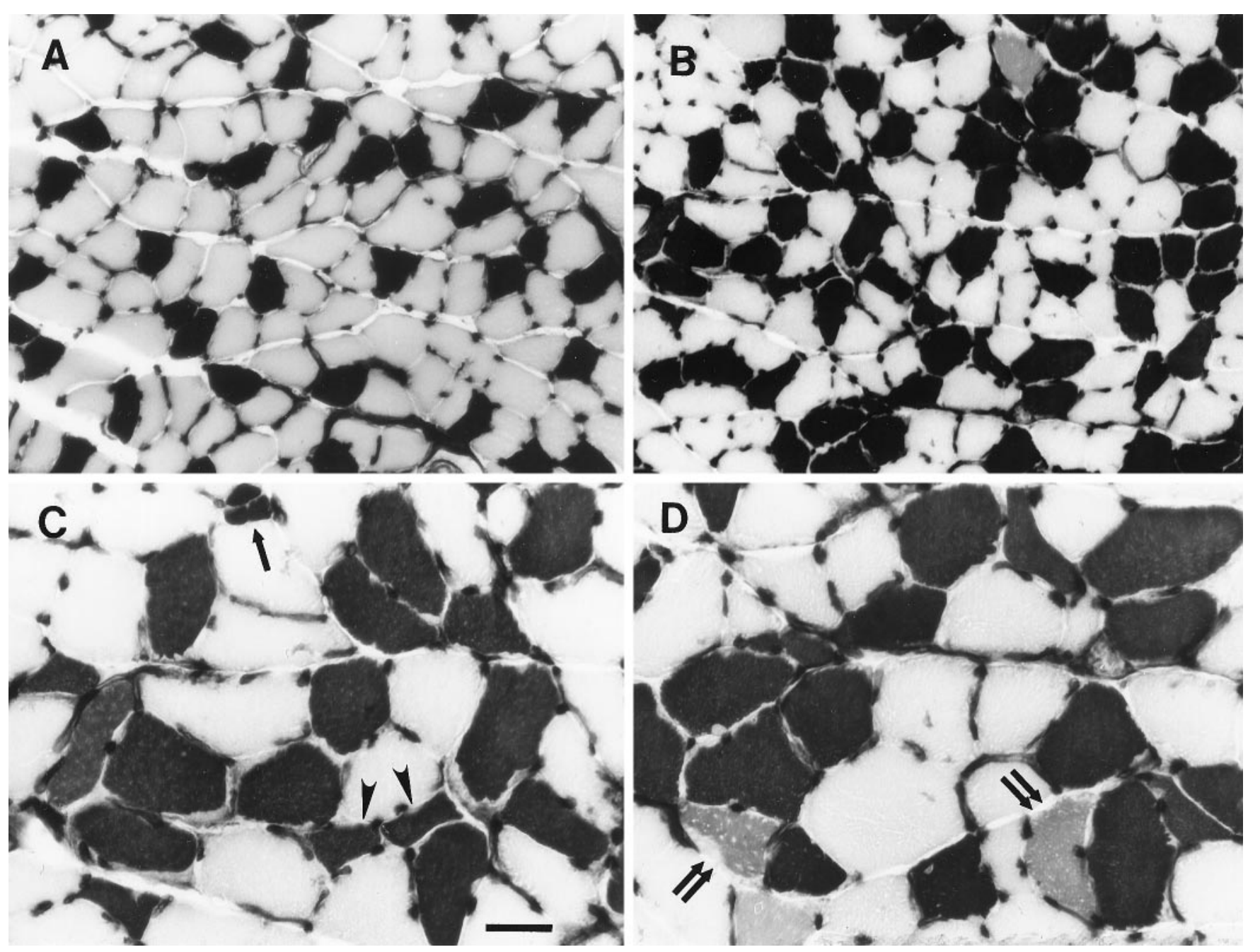

Figure 7. ATPase activity in the gastrocnemius muscle of 6-month-old $\mathrm{P} 0++(A)$ and $\mathrm{P} 0--$ mice $(B-D)$ at $\mathrm{pH} 4.3$. $A$, Labeling for $\mathrm{ATPase}$ activity in gastrocnemius muscle of $\mathrm{P} 0++$ mice reveals the typical checkerboard staining pattern. $B$, In the P0- - mice, type I muscle fibers are grouped. $C, D$, Larger magnification of gastrocnemius muscle of $\mathrm{P} 0--$ mice. Note small groups of atrophic myofibers (arrow), angulated fibers (arrowheads), and fibers of intermediate staining intensity (double arrows), probably reflecting a change of fiber type. Scale bar (shown in $C$ ): $A, B, 25 \mu \mathrm{m} ; C, D, 12.5 \mu \mathrm{m}$. 
substantial axonal loss (Timmerman et al., 1996; De Jonghe et al., 1997). The increased vulnerability of relatively long nerves is most probably responsible for the well known phenomenon that the peroneal muscles and the intrinsic foot muscles of patients are first and most severely affected, followed by muscle atrophy in the hands (Dyck et al., 1993). This leads to irreversible skeletal deformities such as pes cavus and clawhand formation caused by unopposed action of long toe and finger muscles, respectively. In $\mathrm{P} 0--$ mice, muscle atrophy is not as severe as in human. This might be explained by the shorter life span of the animals and also by the reduced vulnerability of the nerves attributable to their shorter extension in a small-sized animal.

The robust loss of axons in at least some forms of inherited neuropathies has important implications for possible treatment strategies. One possibility might be to mimic correct Schwann cell-axon interactions, possibly by activating axonal receptors for glial cell surface molecules with the appropriate ligands. Furthermore, it might be promising to treat the distal aspects of the nerves with trophic factors in the hope of preventing or reducing axonal loss. A promising approach has recently been presented by Haase et al. (1997) using adenoviral vectors for gene transfer of neurotrophin-3 into muscles of spontaneous mouse mutants suffering from progressive motor neuronopathy. Loss of motor axons could be attenuated, and neuromuscular function was improved. Similar approaches could be of interest in hereditary neuropathies with the aim to rescue axon terminals of particularly severely affected nerves. Alternatively, it might be helpful to foster axonal regrowth or intramuscular sprouting before muscle atrophy will occur. Interestingly, insulin-like growth factor I strongly fosters intramuscular axonal sprouting (Caroni and Grandes, 1990). In addition, this factor accelerates myelination by Schwann cells (Feldman et al., 1997) and therefore could preserve abnormal myelin sheaths that would otherwise be prone to degeneration. The availability of animal models will be instrumental in searching for the appropriate strategies to prevent degenerative processes that result in irreversible degenerative changes in hereditary neuropathies in humans.

\section{REFERENCES}

Adlkofer K, Naef R, Suter U (1997) Analysis of compound heterozygous mice reveals that the Trembler mutation can behave as a gain-offunction allele. J Neurosci Res 49:671-680.

Airaksinen MS, Koltzenburg M, Lewin GR, Masu Y, Helbig C, Wolf E, Brem G, Toyka KV, Thoenen H, Meyer M (1996) Specific subtypes of cutaneous mechanoreceptors require neurotrophin-3 following peripheral target innervation. Neuron 16:287-295.

Anzini P, Neuberg DH-H, Schachner M, Nelles E, Willecke K, Zielasek J, Toyka KV, Suter U, Martini R (1997) Structural abnormalities and deficient maintenance of peripheral nerve myelin in mice lacking the gap junction protein Connexin 32. J Neurosci 17:4545-4551.

Archelos JJ, Trotter J, Previtali S, Weissbrich B, Toyka KV, Hartung HP (1998) Isolation and characterization of an oligodendrocyte precursorderived B-cell epitope in multiple sclerosis. Ann Neurol 43:15-24.

Carenini S, Montag D, Cremer H, Schachner M, Martini R (1997) Absence of the myelin-associated glycoprotein (MAG) and the neural cell adhesion molecule (N-CAM) interferes with the maintenance, but not with the formation of peripheral myelin. Cell Tissue Res 287:3-9.

Carenini S, Montag D, Schachner M, Martini R (1999) Subtle roles of neural cell adhesion molecule and myelin-associated glycoprotein during Schwann cell spiralling in $\mathrm{P} 0$-deficient mice. Glia, in press.

Caroni P, Grandes P, (1990) Nerve sprouting in innervated adult skeletal muscle induced by exposure to elevated levels of insulin-like growth factors. J Cell Biol 110:1307-1317.

Colello RJ, Pott U, Schwab ME (1994) The role of oligodendrocytes and myelin on axon maturation in the developing rat retinofugal pathway. J Neurosci 14:2594-2605.
De Girolami U, Nachmanoff DB, Specht LA (1997) Diseases of skeletal muscle. In: Neuropathology (Garcia JH, Budka H, McKeever PE, Sarnat HB, Sima AAF, eds), pp 717-763. St. Louis: Mosby.

De Jonghe P, Timmerman V, Nelis E, Martin JJ, Van Broeckhoven C (1997) Charcot-Marie-Tooth disease and related peripheral neuropathies. J Peripher Nerv Syst 2:370-387.

De Waegh SM, Brady ST (1990) Local control of axonal properties by Schwann cells: neurofilaments and axonal transport in homologous and heterologous nerve grafts. J Neurosci Res 30:201-212.

De Waegh SM, Lee VM, Brady ST (1992) Local modulation of neurofilament phosphorylation, axonal caliber, and slow axonal transport by myelinating Schwann cells. Cell 68:451-463.

Dyck PJ, Chance PF, Lebo R, Carney JA (1993) Hereditary motor and sensory neuropathies. In: Peripheral neuropathy (Dyck PJ, Thomas PK, Griffin JW, Low PA, Poduslo JF, eds), pp 1094-1136. Philadelphia: W.B. Saunders.

Feldman EL, Russell JW, Cheng H-L (1997) Insulin-like growth factor-I (IGF-I) promotes the myelination of sensory neurons. In: Peripheral nerve society abstracts, p 47. Cambridge, UK: Peripheral Nerve Society.

Fruttiger M, Montag D, Schachner M, Martini R (1995a) Crucial role for the myelin-associated glycoprotein in the maintenance of axon-myelin integrity. Eur J Neurosci 7:511-515.

Fruttiger M, Schachner M, Martini R (1995b) Tenascin-C expression during Wallerian degeneration in C57BL/Wlds mice: possible implications for axonal regeneration. J Neurocytol 24:1-14.

Garcia A, Combarros O, Calleja J, Berciano J (1998) Charcot-MarieTooth disease type $1 \mathrm{~A}$ with $17 \mathrm{p}$ duplication in infancy and early childhood: a longitudinal clinical and electrophysiologic study. Neurology 50:1061-1067.

Giese KP, Martini R, Lemke G, Soriano P, Schachner M (1992) Mouse $\mathrm{P} 0$ gene disruption leads to hypomyelination, abnormal expression of recognition molecules, and degeneration of myelin and axons. Cell 71:565-576.

Haase G, Kennel P, Pettmann B, Akli S, Revah F, Schmalbruch H, Kahn A (1997) Gene therapy of murine motor neuron disease using adenoviral vectors for neurotrophic factors. Nat Med 3:429-436.

Hämäläinen N, Pette D (1993) The histochemical profiles of fast fiber types IIB, IID, and IIA in skeletal muscles of mouse, rat and rabbit. J Histochem Cytochem 41:733-743.

Hsieh ST, Kidd GJ, Crawford TO, Xu Z, Lin WM, Trapp BD, Cleveland DW, Griffin JW (1994) Regional modulation of neurofilament organization by myelination in normal axons. J Neurosci 14:6392-6401.

Marrosu MG, Vaccargiu S, Marrosu G, Vannelli A, Cianchetti C, Muntoni F (1998) Charcot-Marie-Tooth disease type 2 associated with mutation of the myelin protein zero gene. Neurology 50:1397-1401.

Martini R (1997) Animal models for inherited peripheral neuropathies. J Anat 191:321-336.

Martini R, Zielasek J, Toyka KV, Giese KP, Schachner M (1995a) Protein zero $(\mathrm{P} 0)$-deficient mice show myelin degeneration in peripheral nerves characteristic of inherited human neuropathies. Nat Genet 11:281-286.

Martini R, Mohajeri MH, Kasper S, Giese KP, Schachner M (1995b) Mice doubly deficient in the genes for $\mathrm{P} 0$ and myelin basic protein show that both proteins contribute to the formation of the major dense line in peripheral nerve myelin. J Neurosci 15:4488-4495.

Martini R, Zielasek J, Toyka KV (1998) Inherited demyelinating neuropathies: from gene to disease. Curr Opin Neurol 11:545-556.

Meier C, Moll C (1982) Hereditary neuropathy with liability to pressure palsies. J Neurol 228:73-95.

Mills LR, Nurse CA, Diamond J (1989) The neural dependency of Merkel cell development in the rat: the touch domes and foot pads contrasted. Dev Biol 136:61-74.

Sahenk Z, Chen L (1998) Abnormalities in the axonal cytoskeleton induced by a Connexin 32 mutation in nerve xenografts. J Neurosci Res 51:174-184.

Sanchez I, Hassinger L, Paskevich PA, Shine HD, Nixon RA (1996) Oligodendroglia regulate the regional expansion of axon caliber and local accumulation of neurofilaments during development independently of myelin formation. J Neurosci 16:5095-5105.

Sander S, Nicholson GA, Ouvrier P, McLeod JG, Pollard JD (1998) Charcot-Marie-Tooth disease: histopathological features of the periph- 
eral myelin protein (PMP22) duplication (CMT1A) and connexin32 mutations (CMTX1). Muscle Nerve 21:217-225.

Scherer SS, Xu YT, Nelles E, Fischbeck KH, Willecke K, Bone LJ (1998) Connexin32-null mice develop demyelinating peripheral neuropathy. Glia 24:8-20.

Sghirlanzoni A, Pareyson D, Balestrini MR, Bellon E, Berta E, Ciano C, Mandich P, Marazzi R (1992) HMSN III phenotype due to homozygous expression of a dominant HMSN II gene. Neurology 42:2201-2204.

Suter U, Welcher AA, Ozcelik T, Snipes GJ, Kosaras B, Francke U, Billings-Gagliardi S, Sidman RL, Shooter EM (1992) Trembler mouse carries a point mutation in a myelin gene. Nature 356:241-244.

Timmerman V, De Jonghe P, Spoelders P, Simokovic S, Lofgren A, Nelis E, Vance J, Martin JJ, Van Broeckhoven C (1996) Linkage and mutation analysis of Charcot-Marie-Tooth neuropathy type 2 families with chromosomes 1p35-p36 and Xq13. Neurology 46:1311-1318.
Trapp BD, Peterson J, Ransohoff RM, Rudick R, Mork S, Bo L (1998) Axonal transection in the lesions of multiple sclerosis. New Engl J Med 338:278-285.

Warner LE, Mancias P, Butler IJ, McDonald CM, Keppen L, Koob KG, Lupski JR (1998) Mutations in the early growth response 2 (EGR2) gene are associated with hereditary myelinopathies. Nat Genet 18:382-384.

Williamson TL, Cleveland DW (1999) Slowing of axonal transport is a very early event in the toxicity of ALS-linked SOD1 mutants to motor neurons. Nat Neurosci 2:50-56.

Windebank AJ, Wood P, Bunge RP, Dyck PJ (1985) Myelination determines the caliber of dorsal root ganglions in culture. J Neurosci 56:1563-1569.

Yin X, Crawford TO, Griffin JW, Tu P, Lee VM, Li C, Roder J, Trapp BD (1998) Myelin-associated glycoprotein is a myelin signal that modulates the caliber of myelinated axons. J Neurosci 18:1953-1962. 